\title{
The concept of "recontextualization": implications for professional, vocational and workplace learning
}

\begin{abstract}
The paper argues that writers from a variety of socio-cultural and -cognitive perspectives have sought in a number of ways to close the assumed longstanding gap between theory and practice in Professional, Vocational and Workplace Learning (PVWL). In contrast, the paper adopts a different stance: it seeks to dissolve that gap, in other words, show it is only a feature of extant theorisation rather than an a priori given. To do so, the paper extends and elaborates the concept of "recontextualisation", which was originally formulated by van Oers (1998) to clarify why Vygotsky operated with a contextual conception of knowing and learning. It accomplishes this extension and elaboration by identifying three principles to reveal why the concept of recontextualization allows us to appreciate why there is not a gap between theory and practice. Secondly, introduces a holistic framework on the mediated relationship between theory and practice in the development of professional and vocational expertise. The paper concludes by arguing that recontextualization is an open concept which writers who draw on socio-cultural and -cognitive traditions could chose to incorporate into their conceptual repertoire to address issues that currently are excluded from, or are marginal concerns within, their research.

Keywords: recontextualisation, judgement, inference, reason, theory and practice
\end{abstract}




\section{Introduction}

Ever since Schön's (1983) celebrated attempt to address the longstanding gap between theory and practice in professional, vocational and workplace learning (a term that is explained later in the paper) through his concept of the "reflective practicum," writers from a variety of socio-cultural and -cognitive perspectives have either sought to develop that concept (Boshuizen, Bromme, and Gruber, 2007; Eraut, 1995; Higgs, \& Titchen 2001) or to establish alternatives approaches. Recent examples of the latter being the development of new models of learning (Gruber and Harteis, 2018), ways to integrate theory and experience (Billett, 2015) or strategies to facilitate boundary crossing (Akkerman and Bakker, 2011; Tuomi-Gröhn and Engeström, 2003). The common thread between the work of the above writers is the acceptance of a gap between theory and practice rather than any rethinking of whether that gap exists.

The argument presented in this paper is that, paradoxically, a debate in CulturalHistorical Activity Theory (CHAT), which started in the late 1980s and now seems to have petered out, about whether Vygotsky did or did not operate with a decontextual conception of human development and knowledge offers a starting point to dissolve the gap by showing that it has never existed. The paper accomplishes this goal by introducing a reformulated version of Van Oers' (1998) concept of "recontextualization." This concept was originally used to show there is a mediated relation, rather than a gap, between, what is referred to, the contextual (i.e. world of experience) and decontextual (i.e. world of theory). The reformulated version of recontextualization reveals this is equally true of theory and practice. 
To make this case, the paper starts by swiftly sketching the parameters of the decontextual debate initiated by Wertsch (1985) in CHAT in the late 90s, before introducing the contextual interpretation of Vygoysky's position on human development that van Oers (1998) formulated with his concept of "recontextualization." The hallmark of that concept being that the purpose of activity (i.e. object) influenced the way in which resources, for example, ideas, are used. The paper then explains that although Van Oers' concept of recontextualisation offers a starting point to dissolve the aforementioned gap in PVWL, it is insufficient because the context and process of recontextalisation were left implicit or a little under-developed in his original formulation. The paper therefore tackles the original underplaying of context and process by elaborating and extending the concept of recontextualization. It accomplishes this task by drawing on the work of the philosophers McDowell (1996) and Brandom (2000). Up to now, McDowell and Brandom's work has been used in CHAT to shed light on the role of reason in Vygotsky's thinking (Bakhurst, 2011; Derry, 2013). The paper adopts a different, albeit related, approach; it interprets McDowell and Brandom as theorists of human activity. It uses their, respective, ideas about the normativity of knowledge and the social practice of learning by inferring to explain the context and process of recontextualisation. This elaboration and extension allows the paper to identify three principles that underpin the reformulated concept of recontextualization, namely purpose, context and process. The paper explores the implications of these principles by firstly, clarifying the meaning of the acronym PVWL. Secondly, using the principles of recontextualization to highlight the normative nature of, and mediated and inferential relation between, theory and practice in PVWL teaching and learning curricula. The paper concludes by presenting a holistic conception of the development 
of professional and vocational expertise throughout a working life. In doing so, it clarifies why recontextualization is an open concept that writers who draw on sociocultural and socio-cognitive traditions could choose to incorporate into their conceptual repertoire. The paper differs therefore in intention from other recent publications that have focused more on the concept of recontextualisation as a way to analyse specific issues, such as work experience.

2. Vygotsky's theory of cultural mediation: from a "decontextual" to "recontextual" interpretation

\subsection{Vygotsky: a "decontextualist" or "recontextualist"?}

In Thinking and Speech (1987), Vygotsky develops an account of the development of human thinking, as van Oers $(1998, p, 135)$ observes, "as a culture-driven process that eventually results in in mastery and appropriation of more highly developed-so-called scientific--concepts under control of both cultural constraints and personal creativity." All forms of knowing are, for Vygotsky, created through social practices and have a mediated relationship with one another. The crucial issue is that different types of social practices however generate different types of concepts, for example, everyday and theoretical. The former emerge, according to Vygotsky (1987, p. 168), from personal and/or collective categorisations of everyday experience whose meanings can be consolidated as they are shared inter-subjectively within different communities. In 
contrast, the latter emerge from specialist forms of social practice such as inquiry and verification associated with disciplinary traditions and are introduced to us through study in educational institutions. The gist of the interpretation van Oers offers of Vygotsky's position could be stated as follows: we may learn in childhood everyday concepts, such as, flower, before we learn the theoretical concepts, such as, lilies and roses, however, we can use those theoretical concepts to broaden our current understanding of everyday phenomena. This is possible, as Vygotsky observed, because theoretical concepts enable us to:

\footnotetext{
Penetrate the inner essence of things, for the nature of things is not disclosed in direct contemplation of one single object or another, but in connections and relations that are manifested in movement and development of the object, and these connect it to the rest of reality. The internal connection of things is disclosed with the help of thinking in concepts, for to develop a concept of some object mean to disclose a series of connections and relations of the object with the rest of reality; to include it in a complex system of phenomena (Vygotsky 1998, p. 54).
}

At first sight, the above argument about the greater analytical power of theoretical as opposed to everyday concepts can appear to convey the impression that Vygotsky was operating with a decontextual conception of human development which privileged theoretical over other types of development. The first person to level this accusation against Vygotsky was James Wertsch. In Vygotsky and the Social Formation of Mind, Wertsch (1985) invoked the principle of "decontextualization of mediational means" to 
characterise the overarching principle of development underpinning Vygotsky's theory and his concept of the ZPD. Wertsch defined this principle as:

"the process whereby the meaning of signs becomes less and less dependent on the unique spatiotemporal context in which they are used" .....quantity can be represented independently of any concrete perceptual context. Indeed quantity can become an abstract object itself instead of a meaning tied to a set of concrete objects (Wertsch, 1985, p.33).

Viewed from this perspective, decontextualization refers to a process of detachment from conditions that constrain the generality of meanings and actions. This definition led Wertsch to claim that Vygotsky assumed that in the course of development, our actions and meanings become less and less determined by the empirical aspects of a situation, in other words, independent from the situation in which the action was originally learned.

The argument Wertsch advanced that Vygotsky operated with a decontextualized conception of human development has influenced several discussions of his work (see inter alia. Derry, 2013; Kirshner and Whitson, 1995, Steffe and Gale, 1995; Wells 1999;). Yet the concept of decontextualisation is, as van Oers (1998, p. 136) argues, in a prescient but rather under-appreciated article, more problematic than its "surface plausibility" implies. He identifies two limitations to Wertsch's interpretation of Vygotsky's theory of cultural mediation and his argument about decontextualization. 
In the case of the former, van Oers (1998, p.135) argues Vygotsky's emphasis that theoretical concepts are part of a system is a recognition on his behalf that such concepts are "embedded" in an "overarching environment", for example, disciplinary traditions. This embeddedness can, according to van Oers, "be interpreted in terms of contextualisation" (ibid), in other words, although disciplinary traditions anchor or stabilise the meaning of a theoretical concept when the same concept is deployed in another context, that context will influence how it is understood and used. Van Oers also implies, but does not really develop his argument, that although Vygotsky wrote about concept formation in childhood and adolescence, he was nevertheless making a generative point about learning theoretical concepts throughout the life-course. That point is theoretical concepts can be resources in their field of origination or in other fields of activity. The implication of this observation will be returned to later in the paper.

In the case of Wertsch's argument about decontextualization, van Oers (1998) argues the concept is characterised by a "semantic problem": decontextualisation is a "negative qualification", indicating that "something does not occur". This, in effect, renders decontextualisation an uninformative notion since it would imply an occurrence of actions in a setting that is not interpreted by the agent. As a consequence, decontextualisaton would mean there is no situation, action or meaning. In the case of the latter, van Oers (1998) acknowledges that Wertsch attributes implicitly the concept of transfer to Vygotsky. This happens because the notion of the decontextualization of mediational means is, in effect, an assertion of the "applicability of mediational means 
in different situations, including situations that are at variance with the original learning situation". The problem here as has been observed by van Oers is that:

"The notion of decontextualization does not satisfyingly provide an explanation for the phenomenon of transfer, as it focuses on the conditions of actions, whereas transfer is a feature of the activities themselves. Moreover, there is no valid theoretical argument showing why an action must be detached from a situation first to be applicable in another situation, and there is no empirical evidence for the necessity of decontextualisation" (van Oers 1987, p. 137).

Despite raising these objections, van Oers $(1998$,$) follows Wertsch and accepts that$ "context is constitutive of meaning" (p. 135), however, he then makes a different move and dissolves the binary opposition between contextual and decontextual by interpreting Vygoysky's position as implying the "progressive recontextualisation" of knowledge (p. 137). van Oers (1988, p. 137) makes this case by bringing together several strands of thought in Vygotsky and Leont'ev's ideas about, respectively, cultural mediation and human activity to offer a unified perspective on their relationship to one another. He accomplishes this goal by firstly, pointing out that Vygotsky's "analysis of human behaviour was predominately formulated in terms of activities or shared activities". This leads him to conclude that this emphasis on shared activities means there are affinities between Vygotsky's position and Leont'ev's (1978) further development of CHAT through his theory of activity and, as such, there is a continuing and constitutive contextual dimension to Vygotsky's position which Wertsch has missed. 
van Oer's (1988) substantiates this claim in the following way. He notes actions are, for Leont'ev, "always contextualized by cultural, personal, and situational factors" and therefore it follows that "context is a result of a personal (mental) or social act of interpretation of an activity" (p. 137). Thus, he concludes Vygotsky was by virtue of his emphasis on joint action implying that we are continually involved in a process of rerather than de-contextualisation (van Oers, 1998).

Secondly, van Oers (1998) develops this line of argument by drawing on Leont'ev's (1978) notion of activity development and the "object of activity", in other words, the way the purpose of an activity can become a motivating force and influence the way in which we use any - conceptual or material - resource to help us address a problem we are working on. Based on this interpretation of the object of activity, van Oers argues (1998) that as we understand a theoretical concept, which has most probably been introduced to us in relation to an educational purpose, we are also positioned to use that concept as a resource to help us enrich our educational or everyday activities (horizontal recontextualization) or as a source of inspiration to generate a new activity (vertical recontextualization). Using the example of the theoretical concept of "number" and the social practice of "play", van Oers (1998, p. 140) illustrates the horizontal conception of recontextualization. He highlights that as young children learn the concept of number as the basis of Mathematics in school, they are positioned to use that concept to expand the repertoire of activities they engage in when they are playing, for example, running a shop. The theoretical concept of number becomes a resource the children use to enhance one of their everyday activities, in this case, pretending to run a shoe shop, and actions they engage in whilst doing so, such as classifying objects, pricing 
them et.c (ibid). These new options are possible because, the children have broadened the repertoire of the activity they are engaged in by commingling a concept they learnt in another context with the practices associated with playing shop. They are now able, therefore, to classify by type, colour, size, etc. Furthermore, the children could, conceivably, broaden the purpose of the activity of playing shop if they recognized that social practices never exist in isolation from one another and the practice of playing shop presupposes the practice of buying commodities from a supplier.

The concept of progressive recontextualisation as originally formulated by van Oers implies a much more generative argument about activity development than his illustrative example does justice to. Interpreted at its broadest, the concept allows us to appreciate that we inhabit a mediated environment where many of the decisions we take are characterised by the interpolation or a meshing together of Vygotsky's asymmetrical conception of the relationship between theoretical and everyday concepts, to develop and enrich extant and to create new activity. Moreover, this meshing together applies throughout the life-course. The contextual and de-contextual binary distinction discussed above and, by extension, the root of the gap between theory and practice has therefore been dissolved by Van Oers. From his perspective, all activity is contextual and can be conceptually separate from, or commingled to create or enrich, another activity, for example, the concept of number and playing shop. There is, however, another dimension to activity development: its distributed and interconnected character. By this I mean, some activities are preconditions for other activities to occur. We shall return to this observation later in the paper. Before doing so, it is necessary to consider two issues which are left rather underdiscussed in the formulation offered by van Oers of 
recontextualization - context and process - through recourse to the work of McDowell and Brandom.

\section{Context and process of recontextualisation}

\subsection{Activity, mediation and normativity}

It is conceivable that the reason Van Oers did not explicitly address the context of recontextualization is because his intention was to critique Wertsch to retrieve Vygotsky's insights about the mediated relationship between theoretical and everyday concepts. As a consequence, Van Oers took the normative basis of activity and knowledge for granted. One way to explicate the normative basis of activity and knowledge and, in the process, appreciate the way in which context that shapes the relationship between theoretical and everyday concepts, is to turn to the work of John McDowell and interpret his philosophical insights about the relationship between mind and world as insights about human activity more generally.

McDowell (1996) was interested in rectifying what he felt had been the misleading picture of the relation between the mind and world that had characterised much philosophy since Descartes: an impression represented by the twin metaphors of 'inside' our minds (i.e. purely subjective) and 'outside' (presumed to be 'real'). He addressed this issue by focusing our attention on the normative context which provides the social basis of all forms of knowledge by arguing that: 
"In characterising an episode or a state as that of knowing, we are not giving a logical description of that episode or state; we are placing it in the logical space of reasons, of justifying and being able to justify what one says" (McDowell 1996, p. xiv).

From McDowell's perspective, all thinking and acting, irrespective as to whether they are purely theoretical, practical or involve the mediation of theory and practice, occurs in the space of reasons. This space is a human creation, in other words, it has been built up over time through contestation and development and, as such, offers us the basis to interpret thinking and acting or assess competing claims. The nub of McDowell's argument is that the space of reasons allows us to respond to reasons that others offer us for their thoughts and actions or that we offer ourselves for our own actions, through which we can determine what course of action we want to take. McDowell is therefore challenging the long-held view in philosophy and elsewhere in the natural and human sciences that we know something as a result of it impinging on our senses. He is instead arguing that the distinctive feature of human contact with the world is that our perception has a conceptual dimension, and that reason is the basis of our intersubjectivity.

To clarify the implications of his argument about the normative basis of all forms of knowledge, McDowell argues that when we engage in any judgement of our experiences "our conceptual capacities are not exercised on non-conceptual deliverance of sensibility. Conceptual capacities are already operative in the deliverance of sensibility 
themselves" (McDowell, 1996, p. 39). By this McDowell (ibid) means, we are not trapped somehow in a conceptual sphere that is unrelated to a world that is presumably 'outside' it, because the conceptual permeates the natural and vice versa; a situation he encapsulates in his phrase, the "unboundedness of the conceptual."

From this perspective, experience is not our apprehension of raw data that we either impose or do not impose limits on, in terms of how we interpret, rather it is an awareness that "things are thus and so" (McDowell 1996, 26). There are, in other words, reasons why the world is organised in a particular way and those reasons are inextricably bound up in our experiences of the world. Returning to the example of playing shop, young children implicitly involve the reasons why shops exist, why they sell different types of products and why different types of products cost different amounts. Their play activity is therefore normative: it is informed by a set of reasons for why things are thus and so when playing shop. McDowell is therefore making an “interdependence" claim (Guile 2010, p. 133): activities, such as running a shop, require concepts (i.e. rules, norms) and conceptual activities (i.e. decision making based on those concepts), and to appreciate why this is the case it is important to understand how the space of reasons has become an embedded part of our everyday life.

McDowell's argument about the unboundedness of the conceptual allows us therefore to return to van Oers' argument that Vygotsky ideas about concept formation are best conceived as a process of re- as opposed to decontextualisation and, in the process, appreciate why the space of reasons, is the context of recontextualization 
(Guile, 2010). The argument that the world is already conceptualised enables us to appreciate that everyday concepts are not totally divorced from the conceptual sphere, and therefore theoretical and everyday concept exist alongside one another in the space of reasons. The critical issue is that theoretical and everyday concepts are underpinned by different sub-sets of reasons or webs of reasons which exist within the wider space of reasons.

To explain how we operate in a web of reasons, McDowell $(1998$, p. 407) follows the German philosophical tradition of Bildung. He maintains therefore that the acquisition of language in general, and the extension and refinement of this process through education, assists us to develop the rational powers constitutive of personhood: powers that enables us to appreciate our self in relation to others and also our views in relation to the views of others. Initiation into a language, as McDowell observed, is:

$$
\begin{aligned}
& \text {...initiation into a going conception of the "space of reasons" ... [so we can] } \\
& \text { understand communication across boundaries between traditions by moving } \\
& \text { out from the basic case, where the horizon is pretty much given (not Given!) } \\
& \text { by the tradition embodied in the language, to the sort of case where } \\
& \text { horizons need to be fused (McDowell, 1996, p. 184). }
\end{aligned}
$$

This very general description of the boundaries that exist between traditions and that can be overcome through fusing horizons, can be interpreted as a McDowellian acknowledgement of the process of recontextualisation. Stated in terms already introduced but then linking them to McDowell, the purpose of an activity influences the way in which a tradition is developed, for example, the combination of biology and 
chemistry to form bio-chemistry or the combination of engineering theory and engineering practice to enable an engineer to develop their form of knowing (in my terms, a process of recontextualisation). For this to happen, participants have to either operate within extant or create new webs of reasons where they can debate the reasons for the development or fusing and determine how to proceed to achieve that goal.

The argument about the fusing of traditions is where we reach the limits of the ways in which McDowell can be drawn on to elaborate and extend the concept of recontextualization. His very general decription of fusing traditions offers an insufficiently fine-grained analysis of the following issues. They are the process by which people develop the capability to articulate their views and respond to the views of others in a web of reasons, and then use that capability to develop and fuse different traditions. For this reason, it is necessary to consider Brandom's (2000) work on the activity of "inference" and its relationship to the space (and web) of reasons.

\subsection{Activty, mediation and inference}

Like McDowell, Brandom also accepts that the distinctive feature of human life is its normativity, in other words, the distinctive feature of our contact with the word is a response to reasons rather than causes. What he makes explicit, however, is that responding to reasons presupposes inferring what follows from thought or action. Taking the everyday phrase "get out of the way" as an example, Brandom (2000, p. 11) 
highlights that we understand its potential implications by understanding the web of reasons which underpins the phrase. This allows us to infer, for example, that we could be about to be knocked over or to become involved in an argument with someone if we respond aggressively to that command.

The reason it is necessary, according to Brandom, to use inference as the primary unit of analysis when participating in theoretical as much as everyday activity is because:

"Utterances and states are propositionally contentful just insofar as they stand in inferential relations to one another: insofar as they can both serve as and stand in need of reasons: (Brandom, 2002, p. 6).

We develop the capability to understand concepts and their relation to activity, according to Brandom, by grasping the relations that obtain between the reasons that underpin that concept, which are associated with the system of thought or action from which a concept originates, and our own reasons for using that concept orally or textually (Guile, 2010). This is because, as Brandom further observed, "...the inferential significance of a belief depends on what else one believes. Thus, the unit of meaning should be taken as the whole theory, not just a single sentence" (Brandom 2000, 167).

From this perspective, when we participate in any social practice we can only form a judgement about, amongst other matters, the meaning of others' utterances (written or oral) by discerning implicitly or explicitly the web of reasons that underpins 
the utterance (and by extension the social practice it is a part of). This is because, for Brandom, (2000), when we speak or write we are "making a claim or expressing a belief" (p. 160) and that claim or belief only becomes intelligible to others as they develop the capability to make a judgement about its respective merits in relation to their own knowledge of the matter, or grasp the reasons advanced to justify the claim and/or belief. We learn how to form judgements about people's utterances, according to Brandom (2000), as we participate in the social practice of giving and asking for reasons, in other words, offering others reasons for our beliefs or actions, asking others for the reasons for their beliefs or actions, and inferring what follows from the different reasons is what informs different utterances. The outcome of this process is the gradual emergence of "...the know-how to discriminate some things that follow from it and some things that don't, and some things that would be evidence for it and some things that would not" (Brandom, 1995, p. 905). We enrich and extend this capability as we firstly, recognise that some claims people put forward will authorise others in virtue of their inferential consequences and secondly, 'learn to keep score' (Ibid.), that is, follow the unfolding logic of a discussion or argument, so we can affirm, query or contest its logic and implications.

The genesis of the social practice of giving and asking for reasons rests therefore on our enculturation into existing traditions. This is because Brandom, in common with Vygotsky and McDowell maintained that human knowing and learning progresses as we engage with culturally and historically established traditions (Derry 2013; Guile, 2010). In doing so, we determine which elements can be treated as "progressive", in other words, resources we can use to develop or transform a tradition (Brandom, 2005, p. 
555). Influenced by the Gadamerian hermeneutic tradition, Brandom (2002, p. 110) argued that we develop culturally and historically as we "retrospectively rationally reconstruct" the traditions we encounter in the course of our lives, that is, understand their origins and development. To do so, we have to identify different perspectives from which an utterance (textual or oral) can be interpreted and this requires us to learn to "talk with a tradition" (Ibid.) in, at least, two senses. The first is to reconstruct the tradition retrospectively so we can ascertain why it has arisen and what are its distinctive claims. The second is to engage in an "immediate reading" (Ibid.), in other words, as we ask others to explain how the tradition is currently being developed in its own terms, or in relation to another tradition, and as we infer what follows from either development.

The concept of tradition which informs and shapes what we are and is subject to reconstitution was deployed by Brandom in a very general way when he made this argument. It is therefore necessary to clarify, as has been pointed out (Guile 2010), that tradition could refer to a discipline, profession or workplace. Moreover, once we treat tradition heterogeneously, that is, open to development, we are in a position to appreciate why Brandom's argument about participation in the giving and asking of reasons to retrospectively reconstruct or engage in an immediate reading of a tradition, can be interpreted as stages within the process of recontextualisation.

Concisely, the giving and asking of reasons is a generative process that underpins all forms of human activity, but one that nonetheless varies according to the purpose of an activity and the interactions between the participants and the tools bound up with that 
activity. Our initial experience of reconstructing is most likely to be to extend or enrich the traditions we are learning or are familiar with, and this involves others in the sense of engaging with people who have contributed to that tradition. Moving from reconstructing to recontextualising includes, at a minimum, being alert to the standpoints of others as well as being willing to work with them towards shared goals. Listening to and understanding others, however, is more than a process of conversational reciprocity. It is instead an inferential process that is based on reaching reasonable agreement about the purpose of intersecting or changing practices by reasoning from either and one's own point of view. In the process, using the conceptual, technological or human resources associated with those practices in new ways - in short, learning collectively to establish a web of reasons that will inform the way in which elements of an extant tradition are recontextualised to serve a new purpose.

\subsection{Principles of recontextualisation}

The above discussion of the normativity of knowledge, the unboundedness of the conceptual and the social practice of inference has made the context and process of recontextualisation explicit. As a consequence, it is now possible to identify the principles that underpin the elaboration and extension of the concept of recontextualisation undertaken in this paper. The first principle reflects van Oers' starting point about recontextualisation namely that the purpose (or object) of an activity influences the way in which participants use cultural tools, for example, ideas, technologies etc., to enrich or enhance an extant activity or to create a new activity. This definition of the relationship between purpose and deployment of cultural tools has 
therefore affinities with Edwards (2010) argument that the object of activity can be viewed as a "problem space to be worked in and transformed" (p. 5) where the way in which people interpret the object motive (i.e. why something is being done and how to do it) calls forth different responses from participants, reflecting their expertise, interests etc. The second principle of recontextualization is that it occurs in a normative context. This principle reflects: (i) McDowell's general argument that claims about why and how to organise practices and make judgements occurs the space of reasons; and (ii) the gradual nuancing of that argument through the introduction of the subsidiary concept the web of reasons to denote a sub-set of reasons, for example, theoretical, professional etc., within the wider space of reasons. This observation anticipates the third principle that operating in a web of reasons entails the role of inference and judgement associated with a particular social practice or intersection of social practices. This principle reflects Brandom's argument that engaging with, and reconstituting extant activity or creating new activity, presupposes participating in the social practice of giving and asking for reasons. This entails inferring what follows in accordance with the norms of an extant tradition's web of reasons or establishing a new web and norms to infer what follows, in accordance with that new tradition.

The three principles of recontextualisation purpose, normativity and inference have a mediated relationship with one another, in other words, they presuppose one another and each principle could, potentially, be the starting point we use to develop or transform a tradition or to create a new tradition. The possibility that traditions can be developed, transformed or created enables us to appreciate that recontextualisation is a multifaceted concept or, alternatively, a concept that could have multiple expressions which, in 
turn, are related to one another. The next section of the paper explores the implications of this suggestion for PVWL, before doing so it is necessary to clarify that term.

\section{Recontextualisation and Professional, Vocational and Workplace Learning (PVWL)}

4.1. The concept of PVWL and the implications of the principles of recontextualisation

Historically, the fields of Professional and Vocational Learning have been conceived of as separate and different from one another. An enduring explanation is that some writers maintain there is an epistemological basis to certain occupations which requires study in a university prior to membership of a profession, as for example, in engineering, medicine and law (Abbott 1988; Freidson, 2001), while writers who focus on vocational education, for example, apprenticeship argue apprentices should be introduced to disciplinary knowledge to complement their practical knowledge (Fuller and Unwin, 2004). What this split between the professions and vocations has always tended to play down, however, is that professional and vocational formation are both concerned with the theory-practice relation. Stated another way, disciplinary knowledge and practice are, irrespective how the former is gained, as central to professional (Eraut, 1994; Higgs and Titchen, 2001) as much as vocational (Fuller and Unwin, 2015; Gonon 2008) formation. Viewed from this perspective, professional and vocational formation entails 
learning to commingle the forms of knowledge taught in professional or vocational curricula along with the forms of knowledge available or developed in workplaces into an embodied professional or vocational form of knowing - hence, the acronym PVWL.

PVWL presupposes therefore the combination of a "learning" and "teaching" curriculum (Lave and Wenger, 1991), because it makes available to learners' through pedagogic practices forms of knowledge embedded in curricula as well as embedded workplace routines embodied in occupational practice. PVWL teaching curricula in universities take one of two main forms. They can either prepare learners to enter a specific occupational field, for example, architecture, engineering, medicine, pharmacy or, alternatively, they can attune learners to issues associated with forms of work that may exist in a single or number of fields, for example, retail management, digital media, business economics.

The next section of the paper uses the principles of recontextualization it is possible to firstly, clarify why PVWL teaching curricula and learning curricula are contextual and underpinned by normative, albeit, slightly different assumptions. Secondly, introduce a holistic framework that encapsulates the mediated relationship between theory and practice in initial and continuing development of professional and vocational expertise. To offer empirical exemplifications of the recontextualization issues described in the section, I have drawn on my discussion of pharmacology and professional practice (Guile, 2014). 
Taking the creation of professional or vocational curricula that are designed to prepare a learner to enter a specific occupational field as our starting point, the principle of purpose allows us to consider the dialogue which occurs between different combinations of the following parties - universities, professional associations, regulatory bodies etc. and employers - rather than accept curricula as a given. The aim of this dialogue is to determine which concepts from different forms of knowledge (i.e. theoretical, legal, workplace etc.) are selected for inclusion to ensure such curricula achieve their agreed purpose. Such curricula are then established through a process of content recontextualization; the outcome being a consensual or a contested process, according to the extent to which the above parties are prepared to negotiate or stipulate the content they feel should be included in a particular curriculum. Once agreement has been reached as regards which concepts will be recontextualised from disciplines, workplaces, professional practice etc., the principle of normativity allows us to appreciate that the ensuing curriculum constitutes the web of reasons in which recontextualised content is introduced to, and understood by, learners.

One way to illustrate content recontextualization is to take the construction of a specific PVWL curriculum - in this case Pharmacy. Typically, a Pharmacy degree consist of, amongst other elements, areas from Chemistry and Biology, for example, Organic Chemistry and Molecular Biology. The primary purpose of their inclusion is to support student pharmacists to understand Pharmacology (Pharmacy's core discipline), as well as to prepare them for clinical practice where they will need to understand the way in which a drug may or may not affect a customer's biological system based on her/his case history. Thus, it follows that Organic Chemistry and Molecular Biology are being 
taught as resources to help student pharmacists to understand their discipline and its professional practice, rather than to prepare them understand Organic Chemistry and Molecular Biology as sub-disciplines within the core disciplines of Biology and Chemistry.

The principle of purpose also allows us to appreciate the extent to which the above goal is accomplished in a PVWL teaching curriculum is influenced by the process of pedagogic recontextualization, in other words, the way in which lecturers' conception of learning predispose them to adopt different approaches to teaching and learning. One way to illustrate this issue is through reference to the classic distinction between transmission and dialogic pedagogy. The adoption of a transmission perspective on learning has generally been acknowledged as predisposing lecturers to conceive of theoretical knowledge decontextually (Bakker and Derry 2011; Edwards 2016; Wells, 1999). From this perspective, lecturers are more likely to see the purpose of pedagogy atomistically, in other words, to assume that "simple terms must be learned prior to those that are more complex or prior to the combination of such terms in judgements before one can reason with those terms" (Bakker and Derry, 2011 p. 12). Moreover, operating with an assumption that knowledge has to be gradually accumulated is more likely to predispose lecturers to explain concepts to learners in relation to their disciplinary origins because they are following the logic of their original discipline, rather than recognising that their primary goal is to assist learners to grasp those concepts as resources to address the dilemmas which will arise in their professional or vocational practice. 
In contrast, the adoption of a dialogic approach to pedagogy is generally held to predispose lectures to conceive of learning as a co-constructed and inferential process (Bakker and Derry, 2011). This positions lecturers who are contributing to professional or vocational teaching curriculum to firstly, recognise such curricula constitute a web of reasons (normative context) that has emerged from a discursive and selective process. Secondly, understand the purpose of their role as to facilitate student learning by assisting them to: (i) appreciate the norms that structure the relationships between, and meaning of, the concepts and methods included in the curriculum they are studying; and, (ii) use their understanding of those relationships and meanings infer the way that extant knowledge is embedded in workplace artefacts and routines or as a resource to infer connections between theory and practice-based tasks or problems, when undertaking a work placement. Returning to the above example of Organic Chemistry and Molecular Biology, a dialogic conception of pedagogy encourages lecturers to establish learning processes that assist student pharmacists to firstly, explore inferentially with them the role of Organic Chemistry and Molecular Biology in the construction and development of their core discipline - Pharmacology. Secondly, appreciate that their pharmacological knowledge is a resource they will draw on when working as a pharmacist and inferring which medicine(s) to recommend in relation to a patient's conditions.

The principles of recontextualisation - purpose, normativity and inference - can also be used reveal the way in which a PVWL learning curriculum is created through two forms of workplace recontextualization as well as the relationship between PVWL teaching and learning curricula. The principle of purpose allows us to clarify that the primary goal of any form of work is to create the conditions to facilitate firstly, the production of goods or 
services and secondly, the development of professional or vocational expertise to ensure the effective production of those goods and services. The principle of normativity allows us to understand the unboundedness of theoretical concepts, legal requirements etc. They have, over time, become embedded in work practices, routines and artefacts to establish a conceptualised work environment or what Lave and Wenger (1991) refer to as the "traditions of practice" and what Bowker and Starr (1999) refer to as "infrastructures." These are both, in turn, underpinned by a web of reasons which influences the way in which particular traditions of practice, for example, classification, are enacted in workplaces, for example, pharmacies. The principle of inference contributes a different insight about workplace recontextualisation. It enables us to shed light on the way in which professional judgement and expertise is developed through participation in a learning curriculum in a work context.

For reasons of space, I will discuss an example of the development of professional judgement in pharmacy in relation to extant traditions in artefacts, routines etc. The initial development of professional judgement, in the case of student pharmacists involves them commingling their theoretical understanding of pharmacology, their burgeoning professional experience, and a patient's description of their particular condition. In many instances, for example, when responding to patients who have straightforward conditions, pharmaceutical judgement is a fairly routine and eventually habituated process of recontextualization involving what could be referred to as, a form of retrospective construction, in other words, inferring which of the typical range of medicines for a particular condition are most suited to a particular patient. When faced 
with more challenging cases that fall outside the limits of normal practice, for example, when a patient is exhibiting several symptoms, student pharmacists supported by more experienced pharmacists have to engage in a more deliberate and nuanced process of recontextualization. In This process entails engaging an immediate reading of, and then potentially progressive development of, a tradition. This will involve them asking a patient about their medical history, medications prescribed, and adverse reactions experienced etc., and inferring from the answers they receive, their pharmacological knowledge as well as their knowledge of the range of possible medicines, which is the most suitable one. They may also even have to prescribe a supplementary medicine to address any side effects that may arise from the main medication. Their judgment in both cases is underpinned by a web of reasons that pertain to the case-in-hand.

4.3 A recontextualization perspective on the development of professional and vocational expertise

Earlier in the paper, I observed that the concept of recontextualization originally formulated by van Oers was more generative than his example of playing school indicated. In light of my elaboration and extension of the concept of recontextualization and the above discussion of PVWL in relation to the principles of recontextualization, I would now like to return to that observation.

My reformulation of the concept of recontextualisation makes explicit that it is the process which facilitates the formation of professional or vocational expertise: it is the way in which learners mediate between their teaching and learning curriculum. It also establishes that it is the cultural and historical forms of mediation via the unboundedness 
of the conceptual which has led to the creation of conceptually-structured professional or vocational practice which dissolves the assumed gap between theory and practice. This line of reasoning allows us to dissolve the assumed distinction between initial and continuing professional or vocational development. Clearly, the challenge for a learner is to participate in the opportunities provided through their teaching and learning curriculum, or to self-generate opportunities, to develop the ability to develop expertise by reasoning in theoretical and conceptually-structured professional or vocational ways. The reason learners have to develop both modes of reasoning is that they are subject to two different modes of assessment: a requirement to express their understanding, on the one hand, in written and oral forms in accordance with academic conventions and warrants (i.e. theoretical reasoning); and, on the other hand, in oral forms in accordance with professional conventions and warrants (i.e. professional reasoning). This conceptually-structured professional or vocational mode of reasoning, however, constitutes the resource for their on-going professional or vocational development. This resource, which is sometimes referred to as, a "form of knowing" (Gheradi, 2010), is further developed by professionals as they move from one workplace to another and, in the process, encounter an increasing array of "non-canonical" (Brown and Duguid, 1991) situations which require an immediate reading and development of their professional or vocational traditions of practice rather than retrospective reconstruction and deployment of those traditions. Diagram 1. below encapsulates visually, the key issues mentioned in the above discussion.

Diagram 1. Here. 


\section{Conclusion}

The paper has shown that when the concept of recontextualisation, which was originally formulated by van Oers (1998) to address the context-decontextual debate in CHAT, is extended and elaborated it is possible to dissolve the longstanding gap between theory and practice, and that gap in PVWL. The paper accomplished this extension and elaboration by accepting the interpretation van Oers presented about: (i) the link between Vygotsky and Leont'ev via the notion of shared activity and that all forms of activity development occur through engagement with the object, or purpose, of an activity; and, (ii) concepts being cultural tools or resources which we can, in principle, continually recontexualise, that is, recast and deploy in new ways in other contexts. The paper pointed out, however, that in making this argument van Oers, on the one hand, underplayed the context and process of recontextualization; and, on the other hand, made a more generative argument than he acknowledged namely that recontextualization is a lifelong process. The paper addressed these shortcomings through recourse to McDowell and Brandom's, respective, ideas about the normativity of, and unboundedness of, knowledge and the social practice of learning by inferring. It used McDowell's ideas about: (i) the normativity of knowledge to explain that all forms of knowledge are underpinned by assumptions and reasons, but, acknowledged that they differ according to the tradition of thought that underpins them (i.e. theoretical, everyday, professional); and (ii) unboundedness of the conceptual to reveal that professional and vocational practices are already embedded with conceptual content as a result of prior recontextualisation. The paper used Brandom's ideas about the social 
practice of inferring to make the process of recontextualisation explicit via the notions of reconstructing and revising traditions, specifically, professional and vocational traditions.

The paper concluded therefore that both writers allow us to appreciate: the mediated inferential relationship between theory and practice; and that the ensuing normativity of that mediated relationship constitutes the context for subsequent recontextualization. Hence it concluded the assumed gap between theory and practice had been dissolved. The paper concluded by: (i) identifying three principles that underpin the reformulated concept of recontextualization - purpose, context and process; and, (ii) using the principles to introduces a holistic framework on the mediated relationship between theory and practice in initial and continuing development of professional and vocational expertise.

The concept of recontextualization is however, even though it emanates from an elaboration and extension of work in CHAT, an open rather than a closed concept. By this I mean, it is possible for other writers to reconceptualise the concept to enable it to become part of their theoretical repertoire as opposed to being predisposed to use the concept strictly in accordance with the CHAT tradition. The reason recontextualisation can be interpreted in this way is because it is operates with an implicit conception of cognition in practice. The elaboration and extension of the concept has made explicit the cognitive dimension in the original formulation of the concept of recontextualization by van Oers. The activity of playing shop was informed by a number of decisions, for example, to play shop rather than to play another game, to play a particular kind of shop 
and so forth, in other words, the exercise of cognition. This is equally the case when someone in a professional or vocational field vocational activity, for example, a student pharmacist, engages in the volitional activity of using their form of knowing, which is based on their commingling of their pharmacological knowledge, professional experience and assessment of a patient, to form a judgement about which medicine to recommend. Such forms of knowing varying, of course, from one professional or vocational practice to another. The net effect of making visible the role of cognition in practice is that the role that reason and judgement play in shaping the constitution and development of different forms of PVWL practice, becomes apparent.

The paper ends therefore by illustrating the above contention that recontextualization is an open concept. It considers firstly the way in which it can shed light on issues that are treated as gaps in socio-cultural writing on boundary crossing, and secondly its potential implications in socio-cognitive or cognitive psychology through reference to the concept of memory.

Taking the widely cited article by Akkeman and Bakker (2011) as an exemplar of the fomer, they identified four different "learning mechanisms" that can take place at boundaries - identification, coordination, reflection, and transformation - and drew attention to the various ways in which sociocultural differences and resulting discontinuities in action and interaction can come to function as resources for development of intersecting identities and practices. This was an important step forward compared with the previous work on boundry crossing in socio-cultural theory (Tuomi-Gröhn and Engeström, 1993; Hoyles et al. 2010). There was nevertheless a 
tendency in Akkerman and Bakker's paper, along with some subsequent work on "connection" in boundry crossing in PVWL (Choi et al. 2017) work to see the issue of learning mechanisms and connection in finite, rather than continuous, terms. By this I mean, the unit of analysis adopted tends to focuses primarily on (in my terms) particular aspect of recontextualization, for example, the school-workplace boundary. The concept of recontextualization may, however, be of interest to the aforementioned writers for the following reasons. It could be used to make more explicit that the outcome of the learning mechasisms or connections learners make through undertaking a work experience or work placement, constitutes the initial development of a conceptuallystructured professional or vocational mode of reasoning. As a consequence, learners are positioned to develop in occupation-specific or occupation-spanning ways when they enter the labour market and also to continue that process of development through their working life. Thus, from the perspective advanced in this paper, the concept of recontextualization is more encompassing than the concept of boundary crossing, though, this does not mean recontextualisation supplants that concept. One reason is that some of the research undertaken under the umbrella of boundary crossing draws on Brandom's concept of inference and, as such, offers interesting insights into types of pedagogic practice associated with the process of recontextualization (Akkerman and Bakker, 2012; Bakker and Derry, 2011; Heusdens et al. 2016).

In the case of writers exploring PVWL issues from socio-cognitive or cognitive perspective, the concept of recontextualization may be of interest because it could, in principal, offer an alternative perspective on some of the kernel concepts 
associated with those perspectives. One example is the concept of memory. Typically, the issue is explored, as a recent book has acknowledged (Gruber and Harteis, 2018), from a computational perspective. This leads researchers to draw on sub-concepts, such as retrieval and application to analyse the use of memory in PVWL. From a recontextualization perspective, memory could be recast as an inferential process involving a retrospective reconstruction of previous experience, and the use of memory in PVWL as having some contextual and mediated characteristics. This might appeal to writers exploring PVWL issues from sociocognitive or cognitive perspective, because it would open up new issues about the exercise of cognition in relation to "expert performance" (Gruber and Harteis, 2018). I appreciate the above suggestion is a little speculative and therefore requires further conceptual and empirical exploration. It is, however, beyond the scope of the paper to tackle those issues

\section{References}

Abbott, A. (1988) The System of the Professions: An essay on the Divisions of Expert Labour, Chicago: University of Chicago Press.

Akkerman, S. \& Bakker, A. (2011). Guest Editors, Special Edition. Learning at the boundary: An introduction. International Journal of Educational Research, 50 (1).

Akkerman, S. F., \& Bakker, A. (2012). Crossing boundaries between school and work during apprenticeships. Vocations and Learning, 5(2), 153-173.

Bakker, A., Derry, J. (2011) 'Lessons from inferentialism for statistics education'. Mathematical Thinking and Learning, 13 (1-2) 5-26. 
Bakhurst, D. (2011). Vygotsky, Philosophy and Education. Chichester: Wiley-Blackwell.

Bowker, G \& Starr, L. S. (1999) Sorting Things Out: Classification and Its Consequences. Cambridge. MIT Press.

Billett, S. (2015) Integrating Practice-based Experiences into Higher Education (Professional and Practice-based Learning). Dodrecht: Springer.

Boshuizen, H., Bromme, R. and Gruber, H. (2007) Eds Professional Learning: Gaps ad Transitions on the Way from Novice to Expert. Klewer: Amsterdam.

Brandom, R. (1994) Making Explicit Cambridge: Harvard University Press.

Brandom. R. (1995) Knowledge and the social articulation of the space of reasons. Philosophy and Phenomenological Research, 55 (4), 895-908.

Brandon, R. (1997) Replies. Philosophical and Phenomenological Research, 57(1) 189-214.

Brandom, R. (2000). Articulating reasons: An introduction to inferentialism. Cambridge, MA: Harvard University Press.

Brown, J.S. and Duguid, P. (1991) Organizational Learning and Communities-of-Practice: Toward a Unified View of Working, Learning, and Innovation. Organization Science, 2(1) 40-57.

Choi, S., Warvik, G-B. and Lindberg, V. (2018) Integration of Vocational Education and Training Experiences: Purposes, Practices and Principles. Dodrecht: Springer.

Derry, J. (2013). Vygotsky and philosophy. London: Wiley Blackwell.

Edwards, A. (2016) A Cultural-historical Approach to Practice: working within and across practices, in J. Lynch et al. (Eds.) Practice Theory: Diffractive readings in professional practice and education (pp.127-140. London: Routledge

Edwards, A. (2010) Being an expert professional practitioner: the relational turn in expertise. Dordrecht: Springer. 
Eraut, M. (1994) Developing Professional Knowledge and Competence London: Falmer Press.

Foreman, Minnick \& Addison Stone (1996) Contexts for Learning. Oxford. Oxford University Press.

Freidson, E. (2001) Professionalism: the Third Logic. Cambridge: Polity Press.

Fuller, A. and Unwin, L. (2105) Contemporary Apprenticeship: International Perspectives on an Evolving Model of Learning. London: Routledge.

Gherardi, S. (2005) Organizational Knowledge: The Texture of Workplace Learning. Chichester: Wiley

Gonon, P. (2009). The Ques for Modern Vocational Education - Georg Kerschensteiner between Dewey, Weber and Simmel. Berne: P.Lang.

Gruber, H, and Harteis, C. (2018) Individual and Social Influences on Professional Learning: Supporting the Acquisition and Maintenance of Expertise (Professional and Practice-based Learning) Springer: Switzerland.

Guile, D. (2010). The learning challenge of the knowledge economy. Rotterdam: Sense.

Guile, D. (2011a). Interprofessional activity in the 'space of reasons': thinking, communicating and acting Vocations \& Learning, 4(2) 93-111.

Guile, D. (2011b). Interprofessional working and learning: objects, reasons and expertise Mind, Culture \& Activity, 18 (4) 342-64.

Guile, D. (2014). Professional knowledge and professional practice as continuous recontextualisation: a social practice perspective in Muller, J. and Young, M.(ed) Knowledge and the Professions, London: Routledge.

Guile, D. (forthcoming) Education, Work and Expertise: "insular", "relational" and "immaterial" perspectives and implications for professional formation. 
Guile, D. and Wilde, R. (forthcoming Journal of Education and Work) 'Articulating value' for clients in a global engineering consulting firm: an "immaterial" perspective on professional expertise.

Higgs, J. \& Titchen, A. (2001) Practice Knowledge and expertise in Health Professions Oxford: Butterworth-Heinemann.

Heusdens, W.T., A. Bakker, A., Baartman, .K.J. and De Bruijn, E. (2016) Contextualising Vocational Knowledge: A Theoretical Framework and Illustrations From Culinary Education, Vocations and Learning. 9.2. 1510165.

Hoyles, C. Noss, R. Bakker, A. and Kent, P. (

Kirshner, D. and Whitson, J. (1997) Situated Cognition: Social, Semiotic and Psychological Perspectives. London: Routledge.

Leont'ev, A. N. (1978). Activity, consciousness, and personality. Englewood Cliffs: PrenticeHall

McDowell, J. (1996). Mind and world (2nd ed.). Cambridge, MA: Harvard University Press Steffe, L. P., \& Gale, J. E. (Eds.). (1995). Constructivism in education. Hillsdale, NJ, US: Lawrence Erlbaum Associates, Inc.

Tuomi-Gröhn, . \& Y. Engeström (Eds.), Between school and work: New perspectives on transfer and bounary crossing. Amsterdam: Pergamon.

van Oers, B. (1998). The fallacy of decontextualization. Mind, Culture and Activity, 5(2), $135-142$.

Vygotsky, L. S. (1987). The collected works of L. S. Vygotsky: Problems of general psychology (Vol. 1, including the volume 'Thinking and Speech'; N. Minick, Trans., R. W. Reiber \& A. S. Carton, (Eds.). New York: Plenum Press. 
Vygotsky, L. S. (1998) The collected works of L. S. Vygotsky: Child Psychology (Vol. 5, M. J. Hall, Trans., R. W. Reiber, Ed., J. Glick, Prologue). New York: Plenum Press.

Wells, G. (1999). Dialogic inquiry: Towards a sociocultural practice and theory of education. Cambridge: Cambridge University Press.

Wertsch, J. (1985) The Social Formation of Mind. Cambridge: Cambridge University Press.

Young, M. and Muller, J. (2014) The Professions, Knowledge and Expertise London:

Routledge 